Vol. 3, No. 2 | July - December 2020

\title{
Dynamic Modeling and Vector Control of AC Induction Traction Motor in China Railway
}

\author{
Mannan Hassan ${ }^{1}$, Muhammad Suhail Shaikh ${ }^{2}$, H.U.K. Jadoon ${ }^{1}$, Rao Atif ${ }^{1}$, \\ Muhammad Usman Sardar ${ }^{3}$
}

\begin{abstract}
:
In this research paper, control of induction motor drive with high-performance characteristics is developed by using vector control, direct-torque control also with the predictive control model. The coordinate transformation has been introduced and established with the mathematical-models of the induction motor (CRH3 high-speed Electric Multiple Units in China Railway) in the two-phase rotating reference frame and the two-phase stationary reference frame. Along-with the discussion of vector control basic principle, the dynamic mathematicalmodel of the induction motor in the two-phase reference frame is presented. Also, the method of the rotor's field orientation in the two-phase reference frame is presented. Based on some metro-traction motor parameters of $2.7 \mathrm{kV}$ and $1 \mathrm{KHz}$ voltages and operating Frequency respectively, MATLAB/Simulink simulation result verifies the principle, control performance, and characteristics of different control strategies, which are comparatively analyzed in detail.
\end{abstract}

Keywords: Induction Motor, Dynamic Modeling, Coordinate Transformation, Vector Control, Model predictive Control, Direct Torque Control

\section{Introduction:}

Owing to the mathematical and computational advantages, the induction motor, which is also called IM. The recent technological development for the application of traction drives has a more important attraction [1]. The corresponding scalar control of the induction motor is relevantly simpler to be implemented, but the variable like torque and flux gives the sluggish response, which is usually inactive, and the control is easily prone to the instable. Hence this occurs because of the fifth or higher-order system effects in their stability equations. To visualize it in more depths, let's have an example like the increasing torque affect slip and slip goes increasing with the frequency and magnetic flux decreases. Then it is noted that flux is varying, but the corresponding control is not accepted at all. It the flux decreases, then it is compensated by the inactive flux control loop, which is feeding in the additional voltage variable. The vector control method permits higher performance control toque component, rotor speed, or position to be achieved from the Induction Motor. The rigid construction, lower maintenance cost, higher stability state torque, and more straightforward controller in design, the induction motor drives are going to become more suitable as an alternate

${ }^{1}$ School of Electrical Engineering, Southwest Jiaotong University, Chengdu 610031, China ${ }^{2}$ Institute of Electrical Engineering, Yanshan University, Qinhuangdao, 066004, P.R.China ${ }^{3}$ Department of Electrical Engineering, Khwaja Fareed University of Engineering \& Information Technology Rahim Yar Khan 
application in the traction system. It is sufficiently possible to take if ud we can regulate large (which is of course, assured with large Vs) Flux of Stators. Nonetheless for torque control, we will demonstrate that if we want to guarantee that uq should be limited to a small set DTC Global Convergence. We will establish this outcome in order to establish. Assume that separations take place and invoke time-scale separations [13].

There are many control strategies, and the most commonly exploited types are the fieldoriented control (FOC) and the direct torque control (DTC) they are commonly used. Techniques, as mentioned above, already have been invented in the early ' 70 s and ' 80 s, respectively [2]. It is demonstrated like the control of induction motor like dc motor with separately excited schematics made it possible to have a high-performance control of ac motors or drives with their applications.

In comparison with the dc-motor like performance, this vector control is also called decoupling, perpendicular, orthogonal or transvector control. Vector control is implementable in both synchronous motor and induction motor drive. Still, there is an excellent room of interest of research in the design of new control techniques for the variable speed operation of induction motor because the induction motors are considered as the most critical industrial load of the electric power system. It is going to be a prevailing fact that electrical energy consumption is effectively reduced with the effective control of the speed of the electric motor drive. Hence, we can have functional conservation of energy.

Field oriented control is effectively implemented to control the induction of motor drives and synchronous motor drives [30]. The control mentioned above technique is developed for the electric motor applications with high performance, which are required to operate efficiently over the rated speed, able to generate the full torque even at stand-still and have the better dynamics in performance which must include the fastest acceleration, the deceleration in its operation. However, this method is getting more attraction in the lower performance application predominantly owing to the motor's size, initial cost, and electric power consumption with this controller based on the field-oriented techniques [5]-[10].

Typical forms of CRH3 is High-speed trains and more and more are becoming In China, popular. Their traction driver systems consist of traction driver systems, A transformer of traction, a converter of traction, and Motors with traction [14]. To improve their performance, detailed simulation results are required. Thus, a suitable simulation method needs to be investigated [15]. On 11 April 2008[11], the first Chinese-built CRH3 (CRH3-001C) was unveiled. The trains are designed to run at $217 \mathrm{mph}(350 \mathrm{~km} / \mathrm{h})$. CRH3-001C reached a top speed of 394.3 $\mathrm{km} / \mathrm{h}$ (245.0 mph) on 24 June 2008 during the Beijing to Tianjin high-speed line test [12].

Nowadays, the researchers are looking forward to having high impact research with practical implications on the variable speed drive with induction motors because this electric machine is considered as a primary building block of industrial load in the electric power system. It has gone through to be a prevailing fact that electrical energy consumption is effectively reduced with the effective control of the speed of the electric motor drive. The most commonly used in the speed and torque control of the induction motor drive is named as voltage control, control of frequency, control of rotor resistance used with the external circuit, the voltage over frequency control because the speed is the slave of frequency, control of flux, control of slip speed, slip power control alongwith all the appropriate control techniques. Here techniques, as mentioned above, are the scalar control techniques of an induction motor. However, these control techniques show the coupling effect and inferior transient response [11-19].

This research article shows the implementation of the vector control method to remove the above mentioned two issues encountered with induction motor-based drives. Our aim of using the vector control method is to decompose the stator current with 
component generating magnetic-field Ids and component generating torque IQs. Both the components can be individually controlled to have higher performance induction motor based electric drive in comparison with the dc motor bases drive [2]-[4].

This structure has several important advantages: concepts are very intuitive and easy to understand, it can be applied to a wide range of systems, it is easy to consider the multivariable case, dead times can be compensated, easy inclusion of non-linearities in the model, simple handling of constraints, it is easy to implement the resulting controller, this methodology is appropriate for the inclusion [20-29].

This research article illuminates the transient modeling of induction motor with vector control, speed control of induction motor based electric drive, and hence the control of induction motor is verified in the Simulink-MATLAB software. By the recent research with the practical implementations, it has appeared that the vector control method for electric drives has become dominant over the scalar control, and this will be effectively implemented in the industry as a standard.

\section{Dynamic Modeling of AC Asynchronous-Motor}

\section{A. Mathematical Modeling of a synchronous Motor in Three-phase Stationary coordinate system}

The dynamic mathematical prototypical model of induction motor is a higher-order, non-linear, strong-coupled multi-variable coordination system.

Its static and dynamic characteristics and control technology are far more complex than DC motors. To improve system performance, optimize control modes, and improve design methods, it is mandatory to discuss the mathematical model of the particular electric motor further.

Assumption:

1. Set the magnetomotive force generated by the symmetry of the three-phase windings to be distributed along with the sinusoidal law round the air-gap field.

2. Let us ignore the saturation of the magnet circuit. The self-inductances and mutual inductances of each winding are the linear functions.

\section{Core losses can be ignored}

4. The effects of variation in the frequency also corresponding temperature change on winding's resistance are not reflected in the calculation.

Under the assumptions mentioned above, the four equations can be obtained.

$$
\left[\begin{array}{l}
u_{A} \\
u_{B} \\
u_{C} \\
u_{a} \\
u_{b} \\
u_{c}
\end{array}\right]=\left[\begin{array}{cccccc}
R_{s} & 0 & 0 & 0 & 0 & 0 \\
0 & R_{S} & 0 & 0 & 0 & 0 \\
0 & 0 & R_{s} & 0 & 0 & 0 \\
0 & 0 & 0 & R_{r} & 0 & 0 \\
0 & 0 & 0 & 0 & R_{r} & 0 \\
0 & 0 & 0 & 0 & 0 & R_{r}
\end{array}\right]\left[\begin{array}{l}
i_{A} \\
i_{B} \\
i_{C} \\
i_{a} \\
i_{b} \\
i_{c}
\end{array}\right]+p\left[\begin{array}{l}
\psi_{A} \\
\psi_{B} \\
\psi_{C} \\
\psi_{a} \\
\psi_{b} \\
\psi_{c}
\end{array}\right] \text { (1) }
$$

Where $\mathrm{uA}, \mathrm{uB}, \mathrm{uC}, \mathrm{ua}, \mathrm{ub}, \mathrm{uc}-$ instantaneous-values of the phase voltages of stator and rotor; iA, iB, iC, ia, ib, ic- instant values of phase currents of stator and rotor; $\Psi \mathrm{A}, \Psi \mathrm{B}, \Psi \mathrm{C}, \Psi \mathrm{a}, \Psi \mathrm{b}, \Psi \mathrm{c}-$ the full flux linkage of each phase winding; $\mathrm{Rs}, \mathrm{Rr}$ - rotor and stator winding resistance.

$\left[\begin{array}{l}\psi_{A} \\ \psi_{B} \\ \psi_{C} \\ \psi_{a} \\ \psi_{b} \\ \psi_{c}\end{array}\right]=\left[\begin{array}{cccccc}L_{S} & L_{\mathrm{AB}} & L_{\mathrm{AC}} & L_{\mathrm{Aa}} & L_{\mathrm{Ab}} & L_{\mathrm{Ac}} \\ L_{\mathrm{BA}} & L_{s} & L_{\mathrm{BC}} & L_{\mathrm{Ba}} & L_{\mathrm{Bb}} & L_{\mathrm{Bc}} \\ L_{\mathrm{CA}} & L_{\mathrm{CB}} & L_{s} & L_{\mathrm{Ca}} & L_{\mathrm{Cb}} & L_{\mathrm{Cc}} \\ L_{\mathrm{aA}} & L_{\mathrm{aB}} & L_{\mathrm{aC}} & L_{r} & L_{\mathrm{ab}} & L_{\mathrm{ac}} \\ L_{\mathrm{bA}} & L_{\mathrm{bB}} & L_{\mathrm{bC}} & L_{\mathrm{ba}} & L_{r} & L_{\mathrm{bc}} \\ L_{\mathrm{cC}} & L_{\mathrm{ca}} & L_{\mathrm{cb}} & L_{r}\end{array}\right]\left[\begin{array}{c}i_{A} \\ i_{B} \\ i_{C} \\ i_{a} \\ i_{b} \\ i_{c}\end{array}\right](2)$

Rotor mutual inductance $\mathrm{L}_{\mathrm{mr}}$ the maximum mutual magnetic flux interlinking with the rotor one-phase winding;

$$
\begin{aligned}
& \mathrm{L}_{\mathrm{ms}}=\mathrm{L}_{\mathrm{mr}}, \\
& \mathrm{L}_{\mathrm{AA}}=\mathrm{L}_{\mathrm{BB}}=\mathrm{L}_{\mathrm{CC}}=\mathrm{L}_{\mathrm{ms}}+\mathrm{L}_{\mathrm{ls}}, \\
& \mathrm{L}_{\mathrm{aa}}=\mathrm{L}_{\mathrm{bb}}=\mathrm{L}_{\mathrm{cc}}=\mathrm{L}_{\mathrm{ms}}+\mathrm{L}_{\mathrm{lr}}
\end{aligned}
$$

Torque equation is described as:

$$
T_{e}=\frac{1}{2} n_{p}\left[i_{r}^{T} \frac{\partial L_{r s}}{\partial \theta_{r}} i_{s}+i_{s}^{T} \frac{\partial L_{s r}}{\partial \theta_{r}} i_{r}\right]
$$

The mathematical equation for the motion if the viscous friction and torsional elasticity 
for drive contrivance of the electric drive's system are neglected, the torque balance equation of the asynchronous motor drive system is

$$
T_{e}=T_{L}+\frac{J}{n_{p}} \frac{d^{2} \theta_{r}}{d t^{2}}=T_{L}+\frac{J}{n_{p}} \frac{d \omega_{r}}{d t}
$$

\section{B. Coordinate Transformation}

Traction inverters are consisting of the voltage-source inverter (VSI) and Coordinate transformation principle

1. Principle of the mmf equivalent

2. Power invariance principle

3. Equivalency in the current transformation matrix within this calculation

4. Equivalency in the voltage transformation matrix

1) transformation with $3 / 2$ rule

Conversion with the transformation between the three-phase stationary reference frame and the two-phase stationary-reference frame is referred to as 3/2 transformations.

Figure 1 drawn above two coordinate systems, let the adequate turns of the individual phase of the three-phase winding be $\mathrm{N} 3$, and the number of turns of the individual phase of two-phase winding is $\mathrm{N} 2$, and $\mathrm{mmf}$ of individual phase is the numerical product of the sufficient number of turn and current.

With the condition as given below;

$$
\text { 3-phase } \mathrm{mmf}=\text { two-phase } \mathrm{mmf}
$$

So as seen in fig. 1

$$
\begin{gathered}
N_{2} i_{a}=N_{3} i_{A}-N_{3} i_{B} \cos 60^{\circ}-N_{3} i_{C} \cos 60^{\circ} \\
=N_{3}\left(i_{A}-\frac{1}{2} i_{B}-\frac{1}{2} i_{C}\right) \\
N_{2} i_{\beta}=N_{3} i_{B} \sin 60^{\circ}-N_{3} i_{C} \sin 60^{\circ} \\
=\frac{\sqrt{3}}{2} N_{3}\left(i_{B}-i_{C}\right)
\end{gathered}
$$

The zero-axis current is also augmented into the conversion, by considering total power before and after the conversion of transformation is equal,

$$
\begin{gathered}
C_{i} C_{u}^{T}=C_{3 / 2} C_{3 / 2}^{T}=E \\
\frac{3}{2}\left(\frac{N_{3}}{N_{2}}\right)^{2}=1,2 K^{2}=1 \\
\text { where } \Rightarrow \frac{N_{3}}{N_{2}}=\sqrt{\frac{2}{3}}, K=\frac{\sqrt{2}}{2}
\end{gathered}
$$

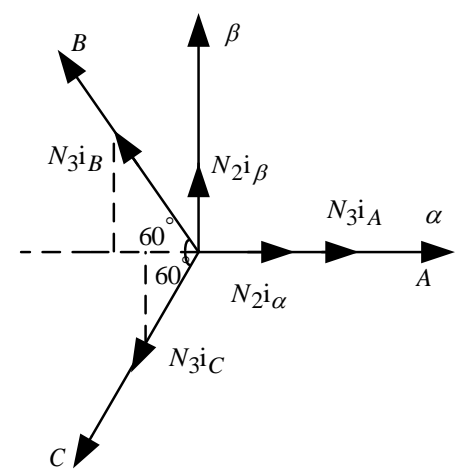

Fig. 1 Vector space of three-phase \& the twophase reference frame and winding's mmf

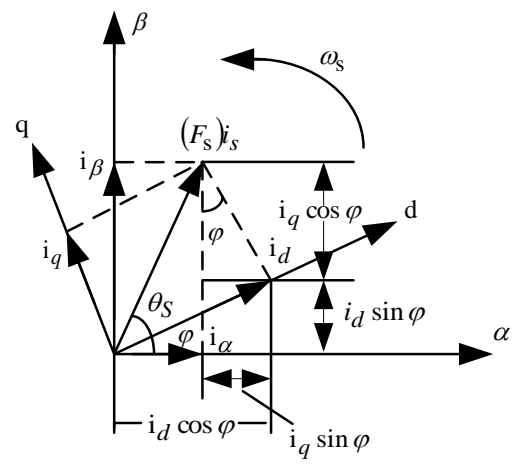

Fig. 2 Stationary and rotating reference frame of two-phase \& mmf

Let $\mathrm{C} 3 / 2$ denote the transformation matrix from the three-phase reference frame to the two-phase coordinate system. Transformation is done from a two-phase reference frame to a three-phase reference frame. In fig. 2 explained the transformation of $\alpha \beta$ stationary frame into $d-q$ rotating frame of $\mathrm{mmf}$.

\section{Mathematic Model of Induction Motor in Two-phase Stationary Reference Frame}

By using Clark transformation to convert the current, voltage, linked flux, and EM torque of the rotor and the stator in equations 
to the two-phase stationary reference frame, the mathematical model of the asynchronous motor in the $\alpha \beta$ reference frame can be

$$
\left[\begin{array}{l}
u_{s \alpha} \\
u_{s \beta} \\
u_{r \alpha} \\
u_{r \beta}
\end{array}\right]=\left[\begin{array}{cccc}
R_{s}+L_{s} p & 0 & L_{m} p & 0 \\
0 & R_{s}+L_{s} p & 0 & L_{m} p \\
L_{m} p & \omega_{r} L_{m} & R_{r}+L_{r} p & \omega_{r} L_{r} \\
-\omega_{r} L_{m} & L_{m} p & -\omega_{r} L_{r} & R_{r}+L_{r} p
\end{array}\right]\left[\begin{array}{l}
i_{s \alpha} \\
i_{s \beta} \\
i_{r \alpha} \\
i_{r \beta}
\end{array}\right]
$$

The torque equation could be depicted as follows.

$$
\begin{aligned}
T_{e} & =\frac{3}{2} n_{p} L_{m}\left(i_{s \beta} i_{r \alpha}-i_{s \alpha} i_{r \beta}\right) \\
& =\frac{3}{2} n_{p}\left(i_{s \beta} \psi_{s \alpha}-i_{s \alpha} \psi_{s \beta}\right)
\end{aligned}
$$

The equation of motion is invariant, $\mathrm{np}$ number of poles, Lm mutual inductions, $\psi_{s \alpha, \beta}$ stator flux, $i_{s \alpha, \beta}$ stator current and $i_{r \alpha, \beta}$ rotor current. It can be seen that the rotating transformation excludes the influence of the angle between the stator and rotor winding on linked-flux and torque. It converts the flux linkage equation of nonlinear variable

$$
\left[\begin{array}{l}
u_{\mathrm{sd}} \\
u_{\mathrm{sq}} \\
u_{\mathrm{rd}} \\
u_{\mathrm{rq}}
\end{array}\right]=\left[\begin{array}{cccc}
R_{s}+L_{s} p & -\omega_{s} L_{s} & L_{m} p & -\omega_{s} L_{m} \\
\omega_{s} L_{s} & R_{s}+L_{s} p & \omega_{s} L_{m} & L_{m} p \\
L_{m} p & -\omega_{\mathrm{sl}} L_{m} & R_{r}+L_{r} p & -\omega_{\mathrm{sl}} L_{r} \\
\omega_{\mathrm{sl}} L_{m} & L_{m} p & \omega_{\mathrm{sl}} L_{r} & R_{r}+L_{r} p
\end{array}\right]\left[\begin{array}{c}
i_{s d} \\
i_{s q} \\
i_{r d} \\
i_{r q}
\end{array}\right]
$$

The torque equation could be depicted as follows.

$$
T_{e}=\frac{3}{2} n_{p} L_{m}\left(i_{s q} i_{r d}-i_{s d} i_{r q}\right)
$$

$\mathrm{np}$ number of poles, Lm mutual inductions, $i_{s d, q}$ stator current and $i_{r d, q}$ rotor current in rotating frame. The above equation of motion is invariant; it is observed that fluxlinkage and torque-equation in the rotating reference frame are similar as in stationary two-phase orthogonal reference frame, and only the subscript changes. The rotating reference frame presents a rotating speed w1, which is the rotating-orthogonal reference frame. When $w 1=0$, the calculated or mathematics model in the rotating reference frame is the same as the mathematical model in the stationary coordinate system, and the introduction of the rotational speed w1 parameters into a steady linear equation. However, the nonlinear coupling of the voltage equation increases.

\section{Mathematic Model of Asynchronous Motor in Two-phase Synchronous Probationary Reference Frame}

Similarly, Park transformation is utilized to convert voltage (V), current (i), flux linkage also the torque of the stator and rotor in the equation to the two-phase rotating reference frame $\mathrm{d}-\mathrm{q}$, and the mathematical model of the asynchronous motor in $\mathrm{d}-\mathrm{q}$ reference frame can be calculated. The voltage equation could be depicted as follows.

improves the degree of freedom of system control. Field-oriented control is achieved by selecting different $w 1$.

\section{Control of AC asynchronous Traction Motor}

\section{A. Fundamental Concepts and Principle of Field-oriented Control}

For mathematical simplification take rotating dq frame, Quadrature and Direct axis. Consider that the d-axis align with the rotor flux vector, which is called the synchronously rotating reference frame aligned with the rotor's flux linkage. Hence d-axis aligns with the vector of the flux of the rotor. Hence accordingly,

$$
\left\{\begin{array}{l}
\psi_{r d}=\psi_{r} \\
\psi_{r q}=0
\end{array}\right.
$$


$\psi_{r d, q}$ is rotor flux, With the purpose to ensure the $\mathrm{x}$-axis and the rotor flux vector always coincide with each other.

$$
\frac{d \psi_{r d}}{d t}=\frac{d \psi_{r q}}{d t}=0
$$

Substituting (11) and (12) into (9), the rotor flux $\Psi_{\mathrm{r}}$ could be depicted as

$$
\psi_{r}=\frac{L_{m}}{T_{r} p+1} i_{s d}=\frac{L_{m}}{\omega_{s l} T_{r}} i_{s q}
$$

Where $\operatorname{Tr}$ nominates the excitation timeconstant of the rotor-flux and hence $\mathrm{Tr}$ $=\mathrm{Lm} / \mathrm{Rr}$. When the isd stays constant, $\Psi \mathrm{r}=$ Lmisd. And the slip angular frequency could be calculated by

$$
\omega_{s l}=\frac{L_{m}}{T_{r} \psi_{r}} i_{s q}=\frac{1+T_{r} p}{T_{r} i_{s d}} i_{s q}
$$

According to the calculation above, the dynamic vector diagram could be drawn as in Fig.1.

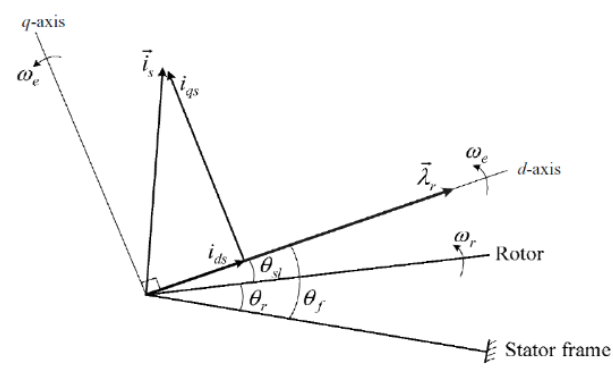

Fig. 3 Rotor flux field orientation (the daxis is aligned with $\lambda r$ ).

Reference of the slip angular frequency could be

depicted

$$
\omega_{s l}^{*}=\frac{i_{s q}^{*}}{i_{s d}^{*}} \frac{1+T_{r} p}{T_{r}}
$$

Thus, the target stator frequency could be calculated as

$$
\omega_{s}^{*}=\omega_{s l}^{*}+\omega_{r}
$$

$$
\varphi=\int \omega_{s}^{*} d t=\int\left(\omega_{s}^{*}+\omega_{r}\right) d t
$$

According to the calculation of angle of motor is based on estimation of angle in (17). the rotor flux $\Psi r$ and phase angle $\varphi$ could be calculated by the current target isd* and isq* according to the structure shown in Fig.4.

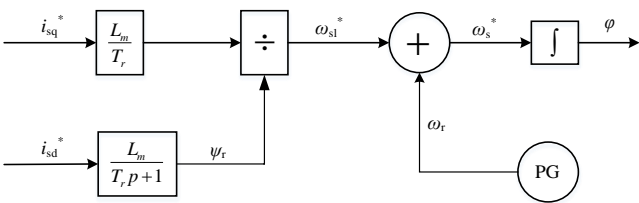

Fig. 4. Calculation structure of $\Psi r$ and $\varphi$

For stability of system in relation of torque and stability the system is Lyapunov stable. if and only $\mathrm{uq}(\mathrm{t})$ is restricted to the open interval $(\mathrm{a}-, \mathrm{a}+)$ that is

$$
u_{q-}>a-, u_{q+}<a+
$$

In other words, the required condition for the system to have a unique point of equilibrium system.

\section{Simulation \& Results}

As per the presented analysis, an indirect field orientation-based control diagram of the induction motor is fabricated, as shown in Fig 5. Through the speed closed-loop, the value of iT is measured with the given value of the speed through the speed close loop, and after that, iT is compared with actual iT to get the voltage $\mathrm{q}$ axis component value through the closed-loop. The given value of iM can be calculated by the given flux at steady-state conditions, through the flux closed loop to get the d-axis component voltage. Then the motor can be driven through the coordinate transformation. The decoupling of current and voltage is achieved in this process through the coordinate transformation. Because of the stator angle is used in the coordinate transformation, so this paper uses the rotor field orientation method to get the slip angular velocity. The detailed principle has been explained above. 


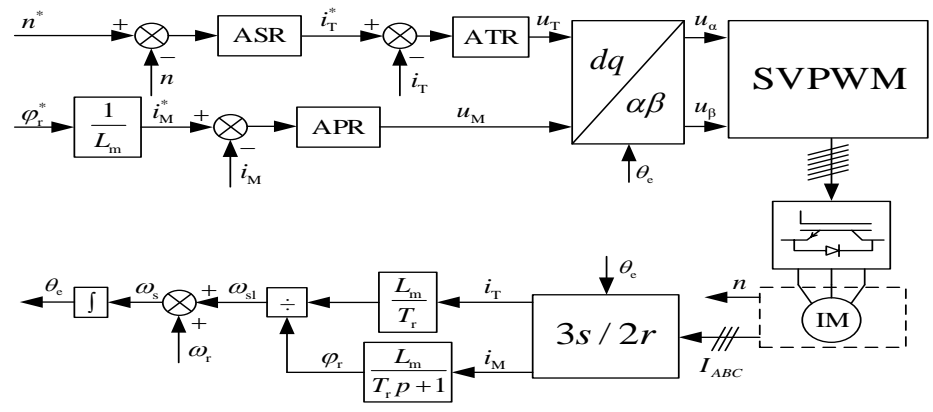

Fig.6 Control block diagram of vector control

The motor parameters and the test case are shown as follows:

Table I: simulation model parameters

\begin{tabular}{|l|l|l|}
\hline $\begin{array}{l}\text { Sym } \\
\text { bol }\end{array}$ & Quantity & Value \\
\hline$P_{\mathrm{N}}$ & Rated power & $562 \mathrm{KW}$ \\
\hline$U_{\mathrm{N}}$ & Rated voltage & $2700 \mathrm{~V}$ \\
\hline$f_{\mathrm{N}}$ & Rated frequency & $138 \mathrm{~Hz}$ \\
\hline$N_{\mathrm{P}}$ & Pole pairs & 2 \\
\hline$T_{\mathrm{eN}}$ & Rated torque & $692 \mathrm{~N} \cdot \mathrm{m}$ \\
\hline$R_{\mathrm{S}}$ & Resistance of stator & $0.1065 \Omega$ \\
\hline$R_{\mathrm{r}}$ & Resistance of rotor & $0.0663 \Omega$ \\
\hline$L_{l \mathrm{~s}}$ & Inductance of stator & $0.00131 \mathrm{H}$ \\
\hline$L_{l \mathrm{r}}$ & Inductance of rotor & $0.00139 \mathrm{H}$ \\
\hline$L_{m}$ & Mutual-inductance & $0.05361 \mathrm{H}$ \\
\hline$n_{\mathrm{N}}$ & Rated speed & $4100 \mathrm{r} / \mathrm{min}$ \\
\hline$U_{\mathrm{dc}}$ & DC-link voltage & $3000 \mathrm{~V}$ \\
\hline$J$ & Inertia & $2 \mathrm{~kg} \cdot \mathrm{m}^{2}$ \\
\hline$S_{\mathrm{N}}$ & Rated slip & 0.001 \\
\hline$f$ & $\begin{array}{l}\text { Switching } \\
\text { frequency }\end{array}$ & $1 \mathrm{KHz}$ \\
\hline
\end{tabular}

\begin{tabular}{|l|l|l|}
\hline$t$ & Simulation time & $2 \mathrm{~s}$ \\
\hline \multirow{2}{*}{$T_{L}$} & Load torque & $0 \mathrm{~s}: 0 \mathrm{~N}$ \\
& & $1 \mathrm{~s}: 1000 \mathrm{~N}$ \\
& & $0 \mathrm{~s}: 1500 \mathrm{rpm}$ \\
$n^{*}$ & Given speed & $0.5 \mathrm{~s}:$ \\
& & $3000 \mathrm{rpm}$ \\
& & $1.5 \mathrm{~s}: \quad 2000$ \\
& & rpm \\
\hline
\end{tabular}

Among the table, the Un represents the rated voltage of the motor, the Udc represents the DC bus supply, the Pn represents the rated power of the motor, the fn represents the rated frequency of the motor, the $\mathrm{Lm}$ represents the excitation inductance, Ls characterizes stator's inductance value, $\mathrm{Lr}$ characterizes inductance, the Rs represents the stator resistance, the $\mathrm{Rr}$ characterizes rotor resistance, np characterizes pole-pair of the induction motor, Ts characterizes sample time used in the modulation, the $\mathrm{J}$ represents the moment of inertia. The simulation results are given below:

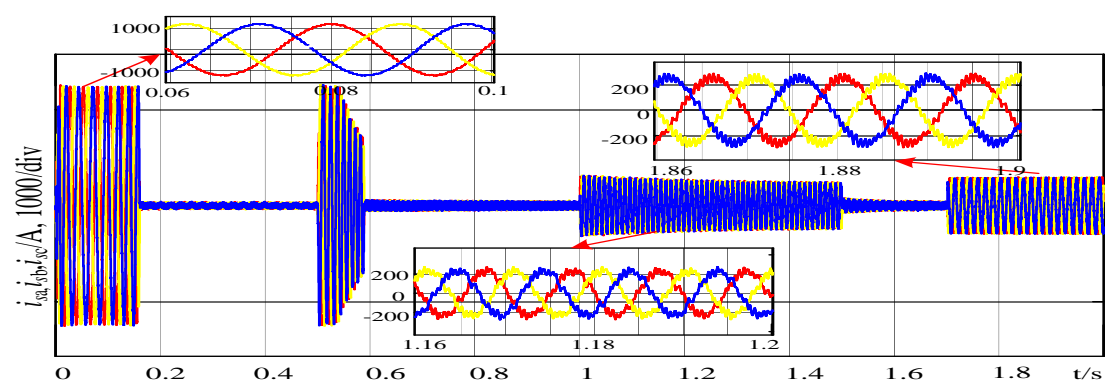

Fig. 7 Three-phase Stator current 


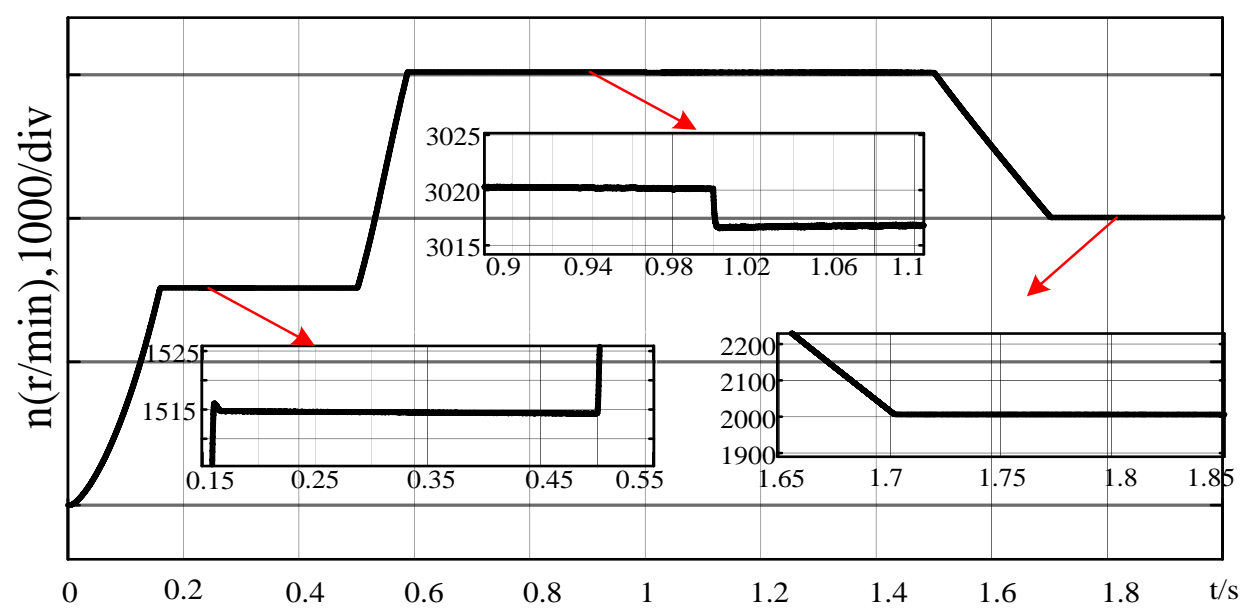

Fig. 8 Output speed

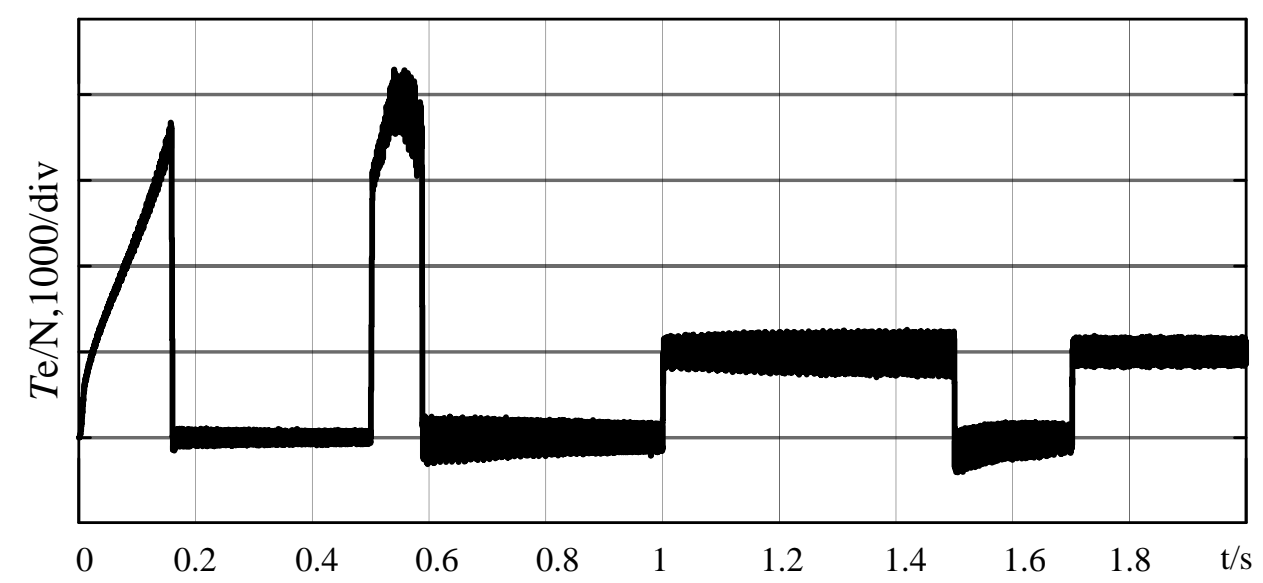

Fig. 9 Output EM torque

It is presented in the simulation that the torque changes quickly, whatever in load torque sudden change or speed sudden change, results in the fast-dynamic performance.

Moreover, the current response quickly, the current is smooth, and the sinusoidally is high. However, at the start time, the torque has two different rising slopes, instead of reaching a constant value quickly. This phenomenon is different from the rapid changes behind because the torque-current component approached the corresponding constant torque, which is calculated at the beginning, showing the correctness of the speed and torque loop parameters.

The rotor flux does not quickly reach the given value but is divided into two slopes in rising, so the flux linkage loop does not reach the desired result.

Since the torque is controlled by both the rotor flux and the current torque component, the torque will not reach the given value if the rotor flux does not reach the given. It is wellknown that in addition to vector control (VC), 
high-performance control of the motor, as well as direct torque control, MPC- model predictive control. The comparative analysis of the VC and DTC are shown in Table II. Moreover, the control performance of the three control strategies is shown in Table III.

Table II: The comparative analysis of dtc and $\mathrm{vc}$

\begin{tabular}{|c|c|c|}
\hline $\begin{array}{l}\text { Performanc } \\
\text { e\& } \\
\text { Characteris } \\
\text { tics }\end{array}$ & DTC & $\mathrm{VC}$ \\
\hline $\begin{array}{l}\text { Flux } \\
\text { control }\end{array}$ & Stator flux & Rotor flux \\
\hline $\begin{array}{l}\text { Torque } \\
\text { control }\end{array}$ & $\begin{array}{l}\text { Bang-bang } \\
\text { control, } \\
\text { with torque } \\
\text { ripple }\end{array}$ & $\begin{array}{l}\text { Continuous } \\
\text { control, } \\
\text { smoother }\end{array}$ \\
\hline $\begin{array}{l}\text { Coordinate } \\
\text { transformat } \\
\text { ion }\end{array}$ & $\begin{array}{l}\text { Clark } \\
\text { transformat } \\
\text { ion } \\
\text { simple }\end{array}$ & $\begin{array}{l}\text { Park } \\
\text { transformat } \\
\text { ion } \\
\text { complicate } \\
\text { d }\end{array}$ \\
\hline $\begin{array}{l}\text { Rotor } \\
\text { parameter } \\
\text { variation }\end{array}$ & No & Yes \\
\hline $\begin{array}{l}\text { Speed } \\
\text { range }\end{array}$ & $\begin{array}{l}\text { Not wide } \\
\text { enough }\end{array}$ & $\begin{array}{l}\text { Relatively } \\
\text { wide }\end{array}$ \\
\hline
\end{tabular}

Table III: The comparative analysis of three control strategies

\begin{tabular}{|c|c|c|}
\hline VC & $>$ & $\begin{array}{l}\text { Limited current loop } \\
\text { bandwidth at the low } \\
\text { switching frequency, Low } \\
\text { dynamic performance } \\
\text { Controller design, the setting } \\
\text { is more complicated, and the } \\
\text { parameter dependence is } \\
\text { stronger. } \\
\text { Need to design complex pulse } \\
\text { mode switching strategies }\end{array}$ \\
\hline
\end{tabular}

\begin{tabular}{|c|c|c|}
\hline & $>$ & $\begin{array}{l}\text { When using off-line } \\
\text { optimized PWM, such as } \\
\text { SHEPWM, the switching } \\
\text { angle is required to be } \\
\text { continuous. }\end{array}$ \\
\hline DTC & $\begin{array}{l}> \\
>\end{array}$ & $\begin{array}{l}\text { Simple structure, fast } \\
\text { dynamic response } \\
\text { Good parameter robustness, } \\
\text { less controller parameters to } \\
\text { debug } \\
\text { When operating it at a low- } \\
\text { switching rate (frequency), } \\
\text { ripple torque in the steady- } \\
\text { state is higher, which is not } \\
\text { suitable for passenger trains } \\
\text { It is difficult to balance } \\
\text { current limiting with transient } \\
\text { process }\end{array}$ \\
\hline $\mathrm{MPC}$ & $>$ & $\begin{array}{l}\text { Simple concept, multi- } \\
\text { objective optimization control } \\
\text { (low switching frequency and } \\
\text { low switching loss), less } \\
\text { debugging parameters } \\
\text { Comparable to the dynamic } \\
\text { performance of DTC and the } \\
\text { steady-state performance of } \\
\text { FOC } \\
\text { Integrated online/offline } \\
\text { synchronization optimized } \\
\text { PWM algorithm for easy } \\
\text { current THD and higher } \\
\text { efficiency than traditional } \\
\text { FOC switch smoothly } \\
\text { Easy to sulse } \\
\text { between any different pulle } \\
\text { modes high } \\
\text { Relatively } \\
\text { computational complexity }\end{array}$ \\
\hline
\end{tabular}

\section{Conclusion}

The parameters of the simulation motor are referred to as the CRH3 EMU. The simulation result verified the principle by analyzing the simulation, and the following conclusions is obtained. The asynchronous motor under the control of the vector adopts the speed and current double-loop structure, the torque response is rapid, and the speed 
changes smoothly. It can have good steadystate performance when the regulator's parameters are suitable. The magnetic field has not yet been fully established in the starting process, so the necessary conditions to guarantee the starting constant torque is to make the rotor flux quickly reach the given value. In addition, because the rotor flux is open-loop in this simulation, the rotor flux cannot make the desired change regardless of how regulator parameters are adjusted, so the starting process is not ideal.

\section{References}

[1] Struharňanský, L'uboš, et al. "Vector Control Techniques for Traction Drive with Induction Machines-Comparison." Procedia engineering 192 (2017): 851856.

[2] Bose, Bimal K. "Power electronics and AC drives." Englewood Cliffs, NJ, Prentice-Hall, 1986, 416 p. (1986).

[3] Krishnan, Ramu. Electric motor drives: modeling, analysis and control. Prentice Hall, 2001.

[4] Mishra, Ambarisha, et al. "Modeling and implementation of vector control for PM synchronous motor drive." IEEEInternational Conference On Advances In Engineering, Science And Management (ICAESM-2012). IEEE, 2012.

[5] Fitzgerald, Arthur Eugene, et al. Electric machinery. Vol. 5. New York: McGrawHill, 2003.

[6] Blaschke, Felix. "The principle of field orientation as applied to the new transvector closed-loop system for rotating-field machines." Siemens review 34.3 (1972): 217-220.

[7] Baader, Uwe, Manfred Depenbrock, and Georg Gierse. "Direct self control (DSC) of inverter-fed induction machine: A basis for speed control without speed measurement." IEEE Transactions on Industry Applications 28.3 (1992): 581588 .

[8] Vas, Peter. Vector control of AC machines. Vol. 22. Oxford University Press, USA, 1990.

[9] Novotny, Donald W., and Thomas A. Lipo. Vector control and dynamics of AC drives. Vol. 1. Oxford university press, 1996.
[10] Vas, P. "Sensorless Vector and Direct Torque Control Oxford University Press." New York, USA (1998).

[11] Tangshan rolls out its first $350 \mathrm{~km} / \mathrm{h}$ train". Railway Gazette International. 11 April 2008. Retrieved 30 June 2008.

[12]Velaro sets Chinese speed record". Railway Gazette International. 27 June 2008. Archived from the original on 22 March 2010. Retrieved 29 May 2010.

[13] Ortega, R., Escobar, G., \& Barabanov, N. (2000, December). Direct torque control of induction motors: Stability analysis and performance improvement. In ISIE'2000. Proceedings of the 2000 IEEE International Symposium on Industrial Electronics (Cat. No. 00TH8543) (Vol. 1, pp. 259-264). IEEE.

[14]Lu, Q. F., Wang, B., Huang, X. Y., Ma, J. E., Fang, Y. T., Yu, J., \& Cao, W. P. (2011). Simulation software for CRH2 and CRH3 traction driver systems based on SIMULINK and VC. Journal of Zhejiang University-SCIENCE A, 12(12), 945-949.

[15]Song, L.M., 2009. The Transmission and Control of EMU. The Chinese Railway Press, Beijing, China, p.134-217 (in Chinese).

[16]Leonhard, W. (2001). Control of electrical drives. Springer Science \& Business Media.

[17] Vas, P. (1990). Vector control of AC machines (Vol. 22). Oxford University Press, USA.

[18]C. French and P. Acarnley, "Direct torque control of permanent magnet drives," IEEE Transactions on Industry Applications, vol. 32, no. 5, pp. 10801088, September/October 1996.

[19]L. Tang, L. Zhong, M. Rahman, and Y. $\mathrm{Hu}$, "A novel direct torque control for interior permanent-magnet synchronous machine drive with low ripple in torque and flux: a speed-sensorless approach," IEEE Transactions on Industry Applications, vol. 39, no. 6, pp. 17481756, March 2003.

[20]T. Geyer, Model Predictive Control of High Power Converters and Industrial Drives. West Sussex, U.K.: Wiley, 2017.

[21] Kumar, Danduproul Kiran. "A MATLAB / SIMULINK MODEL OF PMSM DRIVE USING DIRECT TORQUE CONTROL WITH SPACE VECTOR MODULATION.” (2016).

[22]J. Rodriguez and P. Cortes, Predictive Control of Power Converters and 
Electrical Drives. Hoboken, NJ, USA: Wiley, 2012.

[23] Abad, Gonzalo, ed. Power electronics and electric drives for traction applications. Wiley, 2017.

[24]M. J. Melfi, S. Evon, and R. McElveen, "Induction versus permanent magnet motors," IEEE Industry Applications Magazine, vol. 15, no. 6, 2009.

[25]J. H. Lee, "Model predictive control: Review of the three decades of development," Int. J. Control. Autom. Syst., vol. 9, no. 3, pp. 415-424, 2011

[26] Y. Zhang, B. Xia, H. Yang and J. Rodriguez, "Overview of model predictive control for induction motor drives," in Chinese Journal of Electrical Engineering, vol. 2, no. 1, pp. 62-76, June 2016 , 10.23919/CJEE.2016.7933116.

[27]L. Dube and E. Bayoumi, "Robust DTC Against Parameter Variation for Three Phase Induction Motor Drive Systems," 2020 International Conference on Electrical, Communication, and Computer Engineering (ICECCE), Istanbul, Turkey, 2020, pp. 1-6

[28] A. Ammar, A. Bourek and A. Benakcha, "Efficiency optimization for sensorless induction motor controlled by MRAS based hybrid FOC-DTC strategy," 2017 International Conference on Control, Automation and Diagnosis (ICCAD), Hammamet, 2017, pp. 152-157, doi: 10.1109/CADIAG.2017.8075648.

[29] N. El Ouanjli, A. Derouich, A. Chebabhi and M. Taoussi, "A comparative study between FOC and DTC control of the Doubly Fed Induction Motor (DFIM)," 2017 International Conference on Electrical and Information Technologies (ICEIT), Rabat, 2017, pp. 1-6,'

[30] Y. W. Yhya, R. M. Sharkawy and M. R. Hamouda, "Comparative Study of Different Drive Controller for a Traction System," 2019 21st International Middle East Power Systems Conference (MEPCON), Cairo, Egypt, 2019, pp. 5964. 